\title{
Innovation Management at Vocational Education and Training Institutes: A Necessity to cope with Changing Labor Market Needs
}

\author{
${ }^{1}$ Roger Hessel and Ruken Esra Demirdöğen ${ }^{2}$ \\ ${ }^{* 1}$ Türkiye Ekonomi Politikaları Araştırma Vakfı (TEPAV), Ankara, Turkey; \\ TOBB Economics and Technology University, Faculty of Law, TOBB-ETU Ankara, Turkey \\ ${ }^{2}$ Çankırı Karatekin University, Faculty of Science, Department of Chemistry, Turkey
}

\begin{abstract}
A high-skilled workforce is conditio sine qua non for a high quality of life and economic growth in an ever competitive environment. Vocational education and training institutes often apply teaching methodologies which are out-dated or lack relevance for the labor market needs. The paper analysis how innovative processes can improve the quality of vocational training services. The culture of an organization impacts the degree to which creative, innovative solutions to problems are encouraged and implemented. Promising tools are the support for "innovation teams" and failure-tolerance as well as recruiting trainers with practical, cross-cultural background and skills. Innovative delivery of vocational education and training is also needed to forge stronger linkages between VET and private industries.
\end{abstract}

Keywords: Vocational education and training, innovation, organizational culture

\section{Introduction}

Almost all societies are undertaking a development towards the knowledge society. A high-skilled workforce is the first requirement for a high quality of life and competitiveness of an economy. "Knowledge worker productivity" is the most important challenge for management in the 21 st Century. As technology is increasingly able to not just compute data but synthesize and analyze it, automation will become allencompassing. The knowledge economy is predicated on increased autonomy of workers. Individuals will have to learn to use their skills and knowledge in order to make changes. The exact tasks of a job cannot be anticipated for the next four of five years. Instead, "insight workers", technical and low-skilled workers alike have to deal with these changes and show the necessary autonomy.

At the World Economic Forum this year, which was held in Davos from $23^{\text {rd }}$ to $27^{\text {th }}$ January 2013, innovation was back on top of the agenda. The program consisted of three pillars: "Leading through adversity", "Restoring economic dynamism" and "Strengthening societal resilience" [1]. Indeed, in order to be on the economic rise again, the societal resilience should be strengthened through human capital development provided by high-quality educational institutes. However, education and (vocational) training institutes often deliver ivory tower curricula, based on traditional teaching methodologies which are out-dated and lack relevance for employers and for the young people themselves. In particular the image of vocational training institutes is widely standing in the shadow of higher education institutes, which have at least partly "techno-park" and provide knowledge-transfer on modern sciences and increasingly lecture on managerial skills.

Innovation, here defined as any process of translating an idea or invention into a good or service that creates value or for which customers will pay, is a cornerstone for achieving a higher performance [2].

Innovative management processes could improve the quality and reputation of Vocational Education and Training (VET). Despite it is generally overlooked, VET has much to offer in closing the gap between the world of education and the world of work. It plays a significant role in contributing to development by strengthening innovative capacity and capability of individuals, communities and organizations to introduce new products and processes that are socially, culturally and economically relevant.

*Corresponding author: Roger Hessel, Address: TEPAV Söğütözü Cad. No:43 TOBB-ETÜ Yerleşkesi 2. Kısım 06560 Söğütözü - Ankara, TURKEY. E-mail address: roger.hessel@ tepav.org.tr, phone: +90 5328562705 
One of the crucial policy objectives of the Europe 2020 strategy, the EU's strategy for smart, sustained and inclusive growth, is related to the quality improvement of vocational education and training: VET can be an efficient tool in building human and scientific capital and in improving the capacity of organizations and individuals to adapt new applications of existing information, new products and processes, and new organizational cultures and behaviors. Therefore, improvement of VET systems should be of priority in the agenda of educational and government bodies. VET organizations, as any other entities related to HR development, have to respond to the constant sense of renewal of market conditions and the increased complexity which the world faces today. The innovative capabilities of VET organizations and professionals should be continuously improved by:

- aligning the mandates of VET organizations with development aspirations via innovative approaches to teaching, learning and assessment in VET;

- changing organizational and social cultures, behaviors, incentives and priorities;

- building strong and efficient innovation networks and linkages;

- innovating and implementing new ideas either to replace or to improve existing educational services.

Implementation of innovation in the delivery of VET services is crucial. However, it has to be adapted to different innovation needs of VET managers and teachers and learners so that the innovation's potential to lead growth can be maximized. Success of innovation depends on its agility, speed, impact, its capability to adapt and how much is investigated, experimented, and executed. However, it depends more on the capabilities, willingness and preparedness of individuals, organizations, establishments, societies and countries. They should articulate a clear vision of where they think their future wealth and jobs will come from. Unfortunately, today's world is offering dual tensions such as stability through efficiency, with its opposite, change driven by innovation. The quest for maximizing short-term benefits, cutting risks and managing the fear of the unknown, institutes and individuals focus on stability and efficiency rather than innovation. In the world of VET, more than for instance in the ITdriven sector that fact that innovation drives economic growth is not sufficiently in the focus of attention. The need to cope with the uncertainties of innovation by understanding its dynamics is ever more pronounced given the fast changing needs and expectations of learners who seek to respond to the labor market needs.

Innovation management process consists of seven categories: inputs management, knowledge management, innovation strategy, organizational culture and structure, portfolio management, project management and commercialization [3]. Recent investigations about innovation reveal that institute that innovate successfully and steadily do so by managing innovation holistically in a systematic and integrated fashion across the entire enterprise and in all of their activities related with their customers, partners, suppliers and employees.

Dynamic and deliberative innovation capabilities should be fostered through structuring different mindsets for this purpose. Individuals should become highly collective, collaborative and augmented or in other words they should become amplified individuals who have the characteristics summarized in Table 2. Future innovation capacities should be built on such skills which should exist within the individual's 'natural' skill base based not only on present but also future trends so to allow them become more 'innovation ready' in their skills needed to survive in the future and find fresh innovating opportunities.

As presented in Figure 1 there are six drivers that are shaping the world and there are ten emerging skills where future focus should be placed on in response to changing conditions that will include a higher emphasis on critical thinking, depth of insight and the analysis capabilities to 'translate' the information or data emerging from multiple sources [1]. These necessary skills can be defined and classified under three categories, which are 1) of skills; 2) generic hard skills; 3)specific hard skills. This is presented in Table 1. Specific hard skills are characterized by their lower level of transferability, whereas soft skills and generic hard skills are skills with high transferability across sectors and occupations and can be identified as transversal skills [1]. Transversal skills, which are shown in Figure 2 ranging from problem solving to interpersonal skills are considered as important for innovation. More research should be dedicated to how VET organizations can sustain innovation. Research carried out by Poskiene [4] indicates that a strong and deeply-rooted organisational culture is a primary factor in allowing for sustained innovation [4]. 
According to Poskiene, organisational culture "refers to the complex set of ideologies, traditions, commitments, and values that are shared throughout the organisation and that influence how the organisation conducts its whole performance becoming a potential source of innovation, advance and advantage" [4]. "It is not the values individuals bring to the organisation that count, but the values the organisation brings to the individual" [4]. In line with this definition four attitudes should be met in order to create a successful innovation culture: willingness among corporate managers to take risks, wide-spread participation amongst members of the firm, stimulating creativity, and shared responsibility.

Long-run quality of training services requests a unified culture which values innovation. As summarized in Figure 3 and 4, organizational culture has profound effect on creativity and innovation [5]. This prediction is likely due to the idea that the culture of an organiation impacts the degree to which creative, innovative solutions to questions or problems are encouraged, supported and implemented [6].

\section{Talent management and recruiting innovative talent}

In line with the principles of strategic workforce planning human resources should be used to make it possible for VET organizations to reach their goals via retaining, developing, rewarding and recruiting. Few VET institutes today are using psychometric tests to identify creativity during the personnel selection process, such as the Innovation Potential Indicator (which measures an individual's innovation behaviors) and the Team Selection Inventory (which measures an individual's preferred teamwork climate for innovation). Some HR and VET organizations actively recruit creative people who are difficult to work with - non-conformists who challenge authority and who question the status quo. These qualities, along with a willingness to ask hard questions, can help advance the process of idea generation to idea implementation.

\section{Organizational Structure}

In phase 2 of the innovation process-moving from idea to reality - teams are the most relevant type of organizational structure, according to research. But, working in a team is not always easy, especially given the independent-mindedness of creative people. The most successful teams blend inside and outside perspectives, experience creative tensions, enjoy good leadership, maintain their focus on the client (whether external or internal), and enjoy open dialogue.

Team members have good listening and technical skills, are willing to work hard, know how to have fun, share a passion for the work, and are willing to trust and support one another. Consider adopting the following objectives to build an effective innovation team.

Paul Hofheinz, president of the Brussels think-tank Lisbon Council, believes that the most important skills instructors have to teach is "the ability to formulate complex solutions to unforeseen problems and the capacity to learn new and different skills through-out a lifetime. An education is only an invitation to learn even more" [7]. Hence, VET institutes should aim at recruiting more teachers with practical, international, cross-disciplinary backgrounds, who a capable to respond to new emerging skill needs. Lastly, with cross-functional teams - such as innovation theme teams - and HR tolls to help track progress, VET institutions can make timely advances to meet the challenges of today and tomorrow.

\section{Materials and Method}

This study is descriptive in nature and relies on qualitative data obtained from first-person interviews and received questionnaire replies. A case study methodology was employed and three separate interviews were conducted with school principals whereby the same set of questions will be asked to each. Then, additional data were obtained from more respondents located at the administration or at a bigger VET institution. The questionnaire was developed according to the literature survey made on organizational cultures in general and innovation cultures specifically. All of the variables presented in the hypotheses have been incorporated into the questionnaire. The qualitative data was analyzed in order to provide a clear understanding of each VET school's attitude towards innovation and the likely effectiveness of its innovation culture.

The empirical analysis is addressed to subsidiaries of three large-sized VET schools, the names of which are not disclosed but are indicated with letters A, B and C. VET schools were chosen for analysis because of their reliance on technology and subsequent need to innovate constantly so as to take profit from current trends. Furthermore, these schools emphasize innovation within their mission statements. The 
questionnaire was designed to reveal whether each school actually had an organizational culture conducive to innovation. The questionnaire was offered to eight different departments (computer technologies, computer programming, electricity and energy, electronics and automation, industrial design, electronic communication technologies, and mechatronics) of the school and to first and second year students. The research methodology involves a literature review, analyses, focus group and case studies from different departments in different VET schools. School A values an open and collaborative approach which allows staff, students and companies where the students get their technical trainings to work together. Primary corporate values at School B include dedication towards the success of all of its students and staff, producing innovations, and building relationships which are based upon trust and responsibility. The school claims to be committed to innovation. The school believes that innovation driven by collaboration is the right path towards generation of some of the truly revolutionary innovations. School $\mathrm{C}$ is committed to excellence, innovative activities and overall innovation. The graduates of the school have, however, some difficulty in finding well paid jobs. The school has good links with companies.

\section{Tables and Figures}

\subsection{Tables}

Table 1. Suggested Soft Skill Cluster; Source: European Union, 2011 report

\begin{tabular}{|c|c|c|c|c|}
\hline \multicolumn{5}{|c|}{ Soft Skills } \\
\hline \begin{tabular}{|c|} 
Personal effectiveness \\
skills cluster
\end{tabular} & $\begin{array}{c}\text { Relationship and } \\
\text { service skills cluster }\end{array}$ & $\begin{array}{c}\text { Impact and influence } \\
\text { skills cluster }\end{array}$ & Achievement skills cluster & $\begin{array}{c}\text { Cognitive skills } \\
\text { cluster }\end{array}$ \\
\hline $\begin{array}{l}\text { *Self-control \& } \\
\text { stress resistance; } \\
\text { * Self-confidence; } \\
\text { * Flexibility; } \\
\text { * Creativity; } \\
\text { * Lifelong learning }\end{array}$ & $\begin{array}{l}\text { *Interpersonal } \\
\text { understanding; } \\
\text { *Customer } \\
\text { orientation; } \\
* \text { Cooperation with } \\
\text { others; } \\
* \text { Communication. }\end{array}$ & $\begin{array}{l}* \text { Impact/Influence; } \\
\text { *Organisational } \\
\text { awareness; } \\
\text { *Leadership; } \\
\text { *Development of } \\
\text { others }\end{array}$ & $\begin{array}{l}\text { *Achievement orientation, } \\
\text { efficiency; } \\
\text { *Concern for order, quality, } \\
\text { accuracy; } \\
\text { *Initiative, proactive } \\
\text { approach; } \\
\text { *Problem solving; } \\
\text { *Planning and organization; } \\
\text { *Information exploring and } \\
\text { managing } \\
\text { * Autonomy. }\end{array}$ & $\begin{array}{l}* \text { Analytical } \\
\text { thinking; } \\
\text { *Conceptual } \\
\text { thinking }\end{array}$ \\
\hline
\end{tabular}

The skills in Cluster I reflect some aspects of an individual's maturity in relation to himself / herself, to others and to work. They are related to performance of an individual when dealing with environmental pressures and difficulties. Cluster II is comprised of those skills which enable people to understand the needs of others and to cooperate with them. Communication skills are linked to all clusters and they are included in this one because of their important role in relationship building and communication with others. The skills in cluster III reflect an individual's influence on others. Managerial competencies are a special subset of this cluster. The essence of cluster IV is a tendency towards action, directed more at task accomplishments than impact on other people. Skills in cluster $\mathrm{V}$ reflect an individual's cognitive processes - how a person thinks, analyses, reasons, plans, thinks critically, identifies problems and situations and formulates explanations, hypotheses or concepts. 
Table 2. Characteristics of Amplified individuals

\begin{tabular}{|l|l|}
\hline \multicolumn{2}{|c|}{ AMPLIFIED INDIVIDUALS } \\
\hline highly social & $\begin{array}{l}\text { use tagging software, wikis, social networks, and other human intelligence aggregators } \\
\text { - to supplement their individual knowledge and } \\
\text { - to understand what their individual contributions mean in the context of the organization, } \\
\text { giving meaning to even the most menial tasks }\end{array}$ \\
\hline highly collective & $\begin{array}{l}\text { taking advantage of online collaboration software, mobile communications tools, and } \\
\text { immersive virtual environments to engage globally distributed team members with highly } \\
\text { specialized and complementary capacities. }\end{array}$ \\
\hline highly improvisational & $\begin{array}{l}\text { capable of banding together to form effective networks and infrastructures, both social and } \\
\text { professional }\end{array}$ \\
\hline highly augmented & $\begin{array}{l}\text { employ visualization tools, attention filters, e-displays, and ambient presence systems to } \\
\text { enhance their cognitive abilities and coordination skills, thus enabling them to quickly } \\
\text { access and process massive amounts of information. }\end{array}$ \\
\hline
\end{tabular}

\subsubsection{Results of the analysis made on the schools}

This section is devoted to present and analyze the data obtained from each VET school via the questionnaire. Each school is studied separately. The

Results from Group 1 reveal that respondents in neither of the class felt strongly that the school held the characteristics typically associated with supporting and encouraging innovation. In only Group 8 the mean score was higher than 4 for grade 1. The majority of the mean scores range between 3 and 4 , indicating a neutral position about the proinnovation statements in the questionnaire. The scores obtained for both grades are fairly similar for Groups 1, 2, 3 and 4, while for Groups 5, 6, 7 and 8 they were significantly different. The ability of the school to produce innovations seems somewhat limited by significant divergences in organizational culture across departments. In Group 5 questions there was a big difference in how each grade felt about the outward looking and open-minded nature of results are presented in the Tables 3, 4 and 5 and in the Figures 5, 6 and 7.

\subsubsection{School A}

management in their respective departments. Grade 1 believes that management was outward looking and open-minded approach to new ideas, beneficial to build a culture more innovation-driven while Grade 2 disagreed. In Group 6 the disagreement was the biggest. Grade 1 agrees that the school allows its students freedom to perform tasks as they deem appropriate and to allocate time during their normal workday towards developing new ideas and projects, while Grade 2 views disagrees. Group 7 believes that the school's organization does not encourage the sharing of new ideas at all. However, Grade 1 sees hope for improvement. Improvement is possible in this area. In Group 8 finally, both grades feel the support of the school in innovative projects and studies. Grade 1 is more positive.

Table 3. School A

\begin{tabular}{|l|l|l|l|l|l|l|l|l|}
\hline & Group I & Group II & Group III & Group IV & Group V & Group VI & Group VII & Group VIII \\
\hline Grade I & 3.28 & 3.01 & 3.05 & 3.1 & 3.8 & 3.82 & 3.1 & 4.3 \\
\hline Grade II & 3.02 & 3.28 & 3.45 & 4.01 & 2.26 & 1.80 & 2.01 & 3.04 \\
\hline
\end{tabular}

\subsubsection{School C}

Table 4. Findings of School C

\begin{tabular}{|l|l|l|l|l|l|l|l|l|}
\hline & Group I & Group II & Group III & Group IV & Group V & Group VI & Group VII & Group VIII \\
\hline Grade I & 2.80 & 4 & 4.45 & 5 & 3.8 & 4.3 & 3.30 & 4.02 \\
\hline Grade II & 2.82 & 4 & 4.45 & 4.2 & 5 & 3.5 & 4.50 & 4.30 \\
\hline
\end{tabular}


The results reveal a strong agreement between both grades. In none of the eight groups the mean scores deviates by more than one full point. The lowest scores are obtained in Group 1, suggesting the respondents view the corporate structure of the school at the departmental level is not dedicated to innovation. The degree of department separation is seen as rigid and so the functional specialization by departments, turning the decision chains too long. This situation unconstructive to innovation might be explained by the need to comply with a set of routines in research and project development activities. Although the results obtained with Group 1 were not so good, for Groups 2 and 3 the results were better. So it can be said that the organizational structure at the departmental level encourages an innovation culture. School C is particularly committed and supportive to innovation, regardless rigidity and bureaucracy at the decision taking level. The remaining scores from Groups 4, 5, 6, 7, and 8, were above 3.5. On the whole, the results lead to conclude that the management style and the students' behavior are conducive to generate an innovative climate in the departments.

\subsubsection{Hypotheses contrast}

In order to fulfill Research Question 1 and to test Hypotheses 1 (Table 5), a set of general components inducing an innovation culture was found through our empirical analysis are:
- Willingness to accept risk

- Emphasis on research and innovation and a proper allocation of resources to these activities

- Supply of unique equipments, devices and services that require a high degree of technological excellence

- Acquisition, support and encouragement of creative students

In accordance with the literature review the empirical results reinforce the belief that the key feature of organizational culture which allows for innovation is the role and attitude displayed by the administration, and the principal's readiness to monitoring the progress of the school in innovation-led activities [8, 9]. This study highlights the need to avoid conflict between mechanisms launched to urge innovative ideas and processes, and the operational efficiency. The results obtained for Question 2 revealed the difficulties in VET institutions to get rid of the rigid, hierarchical and bureaucratic organizational structures. This finding is inconsistent with our literature review which pointed out the risks by a rigid and bureaucratic organizational culture to counteract innovative initiatives $[4,7,10]$. But unexpectedly, the somewhat rigid and bureaucratic corporate structures prevailing in the departments at both School A and C, did not have negative impact neither on the capacity to innovate nor on the innovation-led culture.

Table 5. Acceptance or rejection of the components taking part in Hypothesis 1

\begin{tabular}{|l|l|}
\hline $\begin{array}{l}\text { Hypothesis 1: In the departments of strong VET schools the following characteristics were } \\
\text { expected to be high. }\end{array}$ & Yes/No \\
\hline The school allows its students enough freedom & No \\
\hline The school conducts participative and informal meetings & Yes \\
\hline The administration is outward looking, open-minded and open to external ideas & Yes \\
\hline The school values face-to-face communication & No \\
\hline The school emphasizes creative interaction among all of its students and staff & No \\
\hline The school emphasizes creative interaction among all of its students, staff and businesses & No \\
\hline The school is flexible regarding changing needs & Yes \\
\hline The organizational structure of the company is non-hierarchical & No \\
\hline
\end{tabular}

According to Hypothesis I in departments of prominent VET schools an innovation culture can be generated despite the prevalence of a certain level of rigidity, bureaucracy and hierarchical organizational structure. As pointed out in the Table 6, Hypothesis 2 is rejected. Two of the three schools under analysis recognize a broad presence of most of the components and behaviors gathered in the table, and believed to be detrimental to innovation culture. Similar to Hypothesis 1, these results show that the difficulties related with managing departments in big VET schools prevail over their willingness for implementation of innovative processes. 
Table 6. Results for Hypothesis 2

\begin{tabular}{|l|l|}
\hline $\begin{array}{l}\text { Hypothesis 2: In the departments of strong VET schools the following characteristics were } \\
\text { expected to be high. }\end{array}$ & Yes/No \\
\hline The school is characterized by rigid departmental separation and functional specialization & No \\
\hline The school is a hierarchical and bureaucratic organization & No \\
\hline The school is characterized by long decision chains & No \\
\hline The school provides little personal freedom & Yes \\
\hline The school is risk-averse & Yes \\
\hline The school is characterized by many rules and set procedures & No \\
\hline The school is flexible regarding changing needs & Yes \\
\hline The school is characterized by formal reporting standrads & No \\
\hline
\end{tabular}

\subsection{Figures}

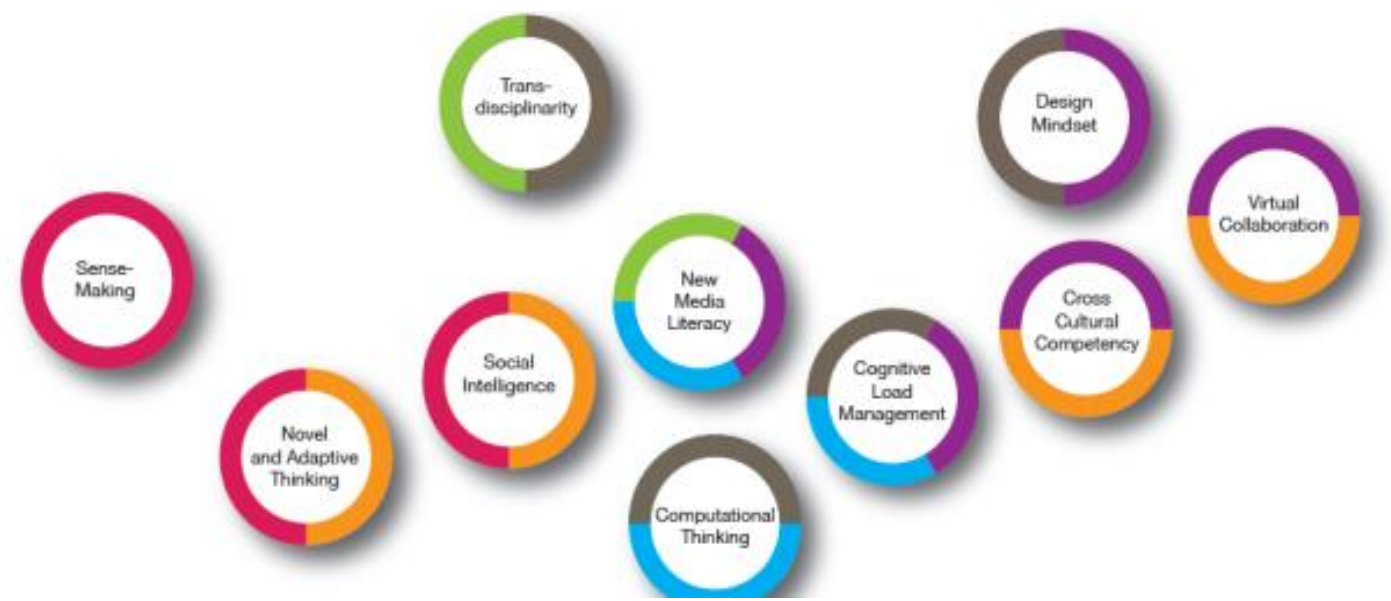

Figure 1. Ten emerging crucial skills.

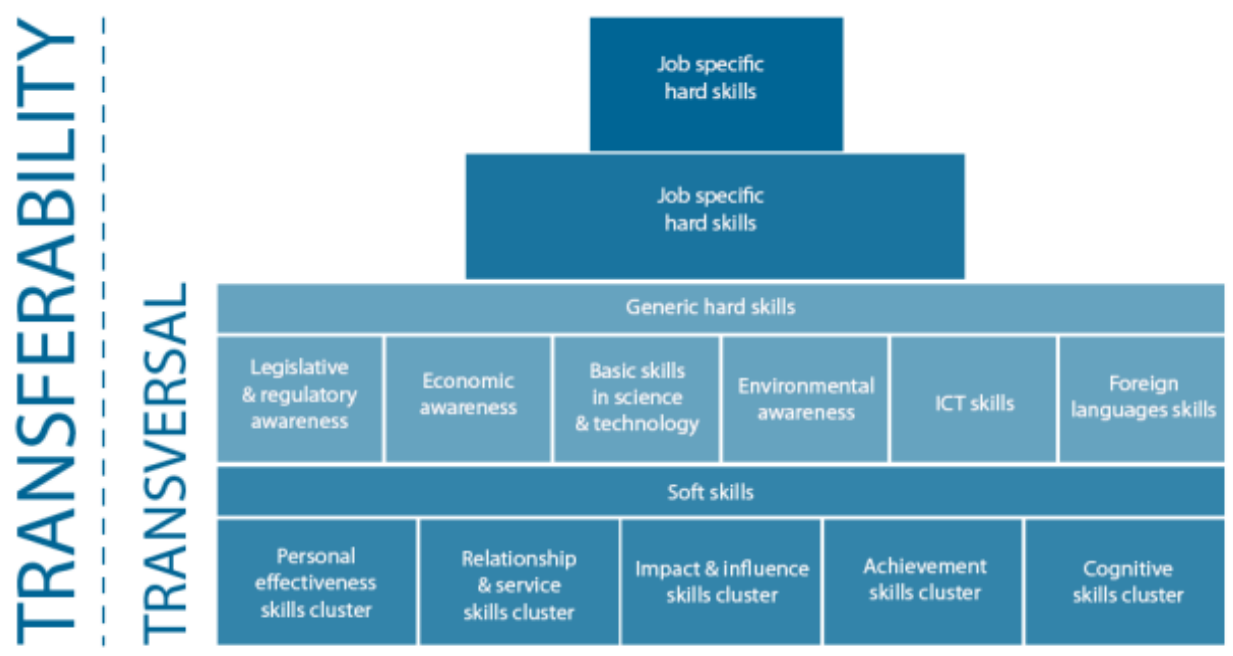

Application of the modular system

Figure 2. Skills Taxonomy by Transferability; Source: European Union 2011 report 


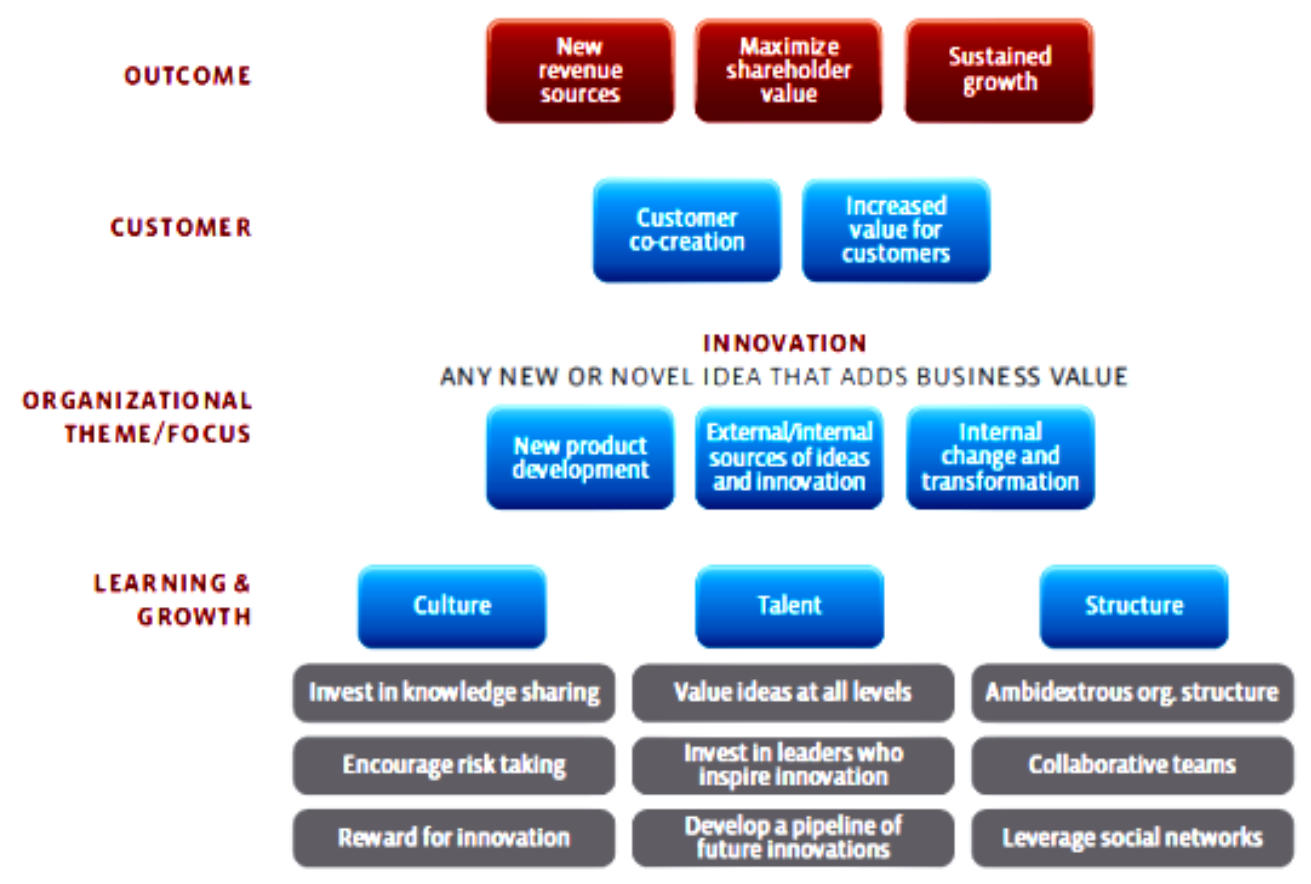

Figure 3. Innovation strategy map

Objectives in the learning and growth perspective clearly and unambiguously support the innovation strategy. Phase 2 is the main concern in this study.

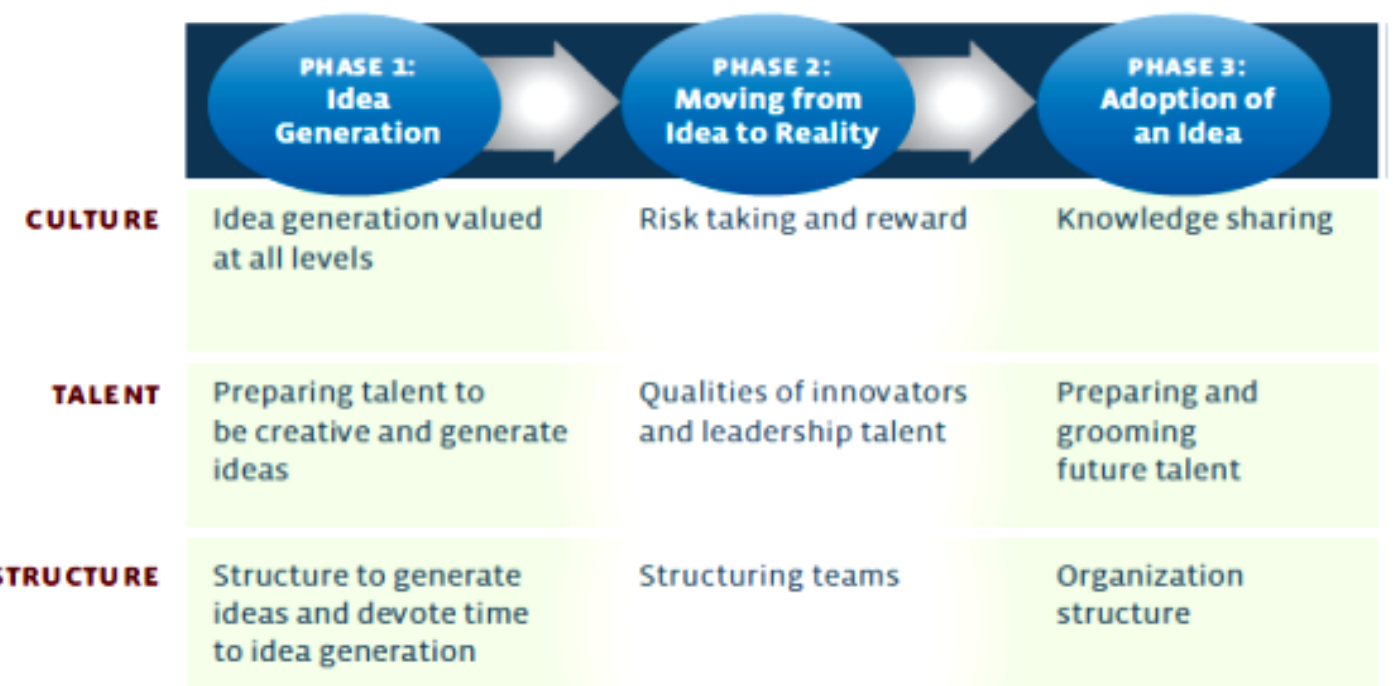

Figure 4. Culture, talent and structure in the innovation process 


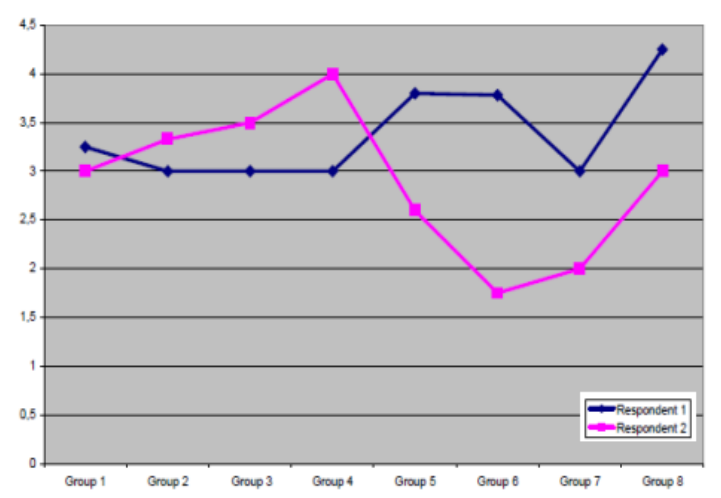

Figure 5. School A

The results are positive and show that the respondents believe that innovation behavior is encouraged in grade 2. The scores for Groups 1, 2, 3, 4, 6 and 8, all above 3,5 points, shows that this grade in the school contain the structure, management style and behavior is adjusted to an innovation culture. The extremely high score for Group 3 indicates that the school allocates significant time and resources to this department and supports its practices. The lowest score is obtained in Group 5. This shows that despite the students are encouraged to think critically, once a final decision is made by the administration the students are then expected to obey. According to the respondent, in Group 7, the students feel comfortable sharing new ideas, but the school does not put forward mechanisms to allow students to learn from mistakes by others.

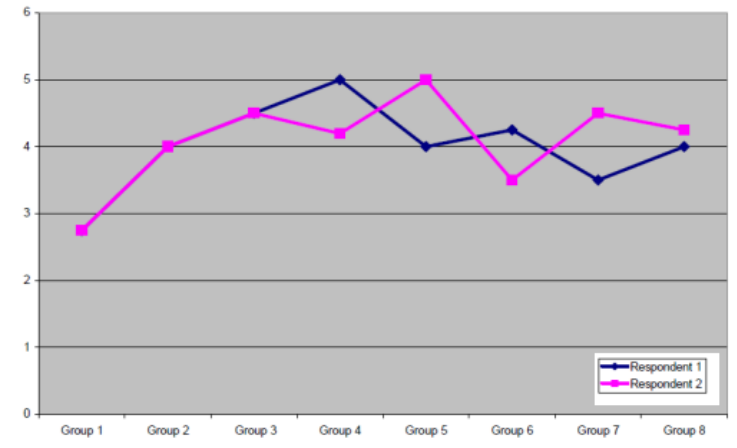

Figure 7. School C

\section{Discussion}

The ability of VET institutes, as of any organization, to produce consistent and beneficial innovations primarily derives from its culture. Although the culture takes a greater role than individuals within the culture of the organization, the significance of the

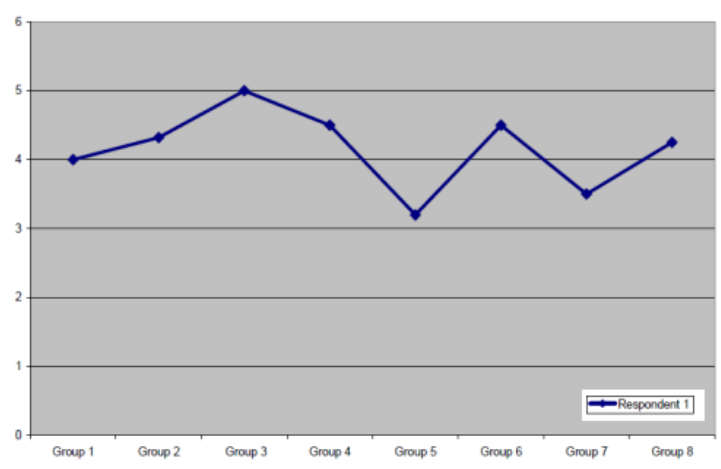

Figure 6. School B

role played by administration should is undeniable. In order to meet the current and future demands of the labor markets and the societies, VET organizations should become fully innovative. In this respect, innovation management, encouraging members of the organization to become creative and actively monitoring the organization's progress are crucial in order to ensure a culture conducive to the constant generation of valuable innovations. The vast majority of the members of the organization are a product of the organization's culture and they have to act in accordance with it. However, the relatively small group of senior managers is the one responsible to stimulate and maintain the organization's culture, and therefore their individual contribution is of great importance.

Although it is believed that the right atmosphere to properly innovate requests open-minded thinking and a relaxed, open and rule-free environment, components that have not been found in the three VET institutes under study. The relatively high degrees of bureaucracy and hierarchical behavior in the organizational structures of the departments of the both School A and C apparently has not prevented them from acquiring high levels of success for a prolonged period of time and a remarkable capacity to develop and launch innovations. Thus, our empirical study reveals that the organizational rigidity, largely believed to hamper the innovative capacity, seem not to have adversely affected the ability to innovate in these schools. However, these results are based on the perceptions of the interrogated individuals and thus are qualitative.

On the other hand it was seen that these schools allocate more time and resources towards research and innovation activities. This in return provides 
competitive advantage. As for management implications, both the literature review and the results of this study show that several behaviors lead to an innovation-driven culture. These are being outward looking, open-minded and willing to consider external ideas, coupled with encouraging students' and staff's creativity and monitoring education practices in order to determine where innovative processes or procedures are needed. Senior managers are expected to conduct frequent meetings in order to openly discuss and debate the ideas of the students, staff and the businesses. If the culture of the organization causes the students and the staff to be timid regarding challenging established practices and procedures, the school's ability to innovate effectively is likely to be reduced. VET schools should allow their staff and students the freedom to think critically about how their roles and career aspects could be improved.

The major finding from this study states that decision makers do not need to be overly concerned with maintaining a loose corporate structure. A significant degree of bureaucracy coupled with a rigid structure does not necessarily inhibit innovation. In fact, for big schools with many departments, a tight structure can be beneficial and necessary in order to operate an efficient and profitable enterprise.

\section{Conclusions}

Generally, no accurate, reliable and widely shared empirically proved method exists for measuring a firm's innovation culture [17]. There is a need in many countries for making better use of current resource, create real professional environment, strengthen practical VET centers and build a steadily practical training base outside normal school.

Key findings about innovation in VET teaching and learning are that:

(1) promoting new educational programs that are more strategically attuned to the societal different needs improve the quality and, hence, the reputation of VET institutes;

(2) more innovation is needed in the VET systems. For this end change should be induced in the cultures of VET organizations through the introduction of educational programs and linkages beyond the formal VET system;

(3) innovation is required to meet the many needs of different learners and the often unpredictable requirements of the future labor market;
(4) strengthening individual and organizational capacity by improving the incentives to forge stronger linkages between VET and diverse user communities and private industries;

(5) innovation results from practitioners' skills and actions; vocational trainer should therefore bring in their industrial experience, ideally also from an international background;

(6) innovation can be fostered or impeded by many factors, e.g. senior management in registered training organizations (RTOs), availability of resources and analysing and overcoming staff resistance and demotivation.

\section{References}

[1] Haubcraft P, The Innovation Bunker - Our Cognitive Traps part one, http://paul4innovating.com/, Posted on May 1, 2013

[2] Drucker PF, Landmarks of Tomorrow: A Report on the New Post-Modern World. Rutgers- The State University, New Brunswick, New Jersey: Transaction Publishers; 2009.

[3] Adams R, Bessant J, Phelps R, Innovation management measurement: $\mathrm{A}$ review, Int $\mathrm{J}$ of Management Reviews, March 2006; 8 (1): 21-47.

[4] Poskiene A, Organizational Culture and Innovations, Engineering Economics, 2006, 46 (1): 45-50.

[5] Martins, E.C., The influence of organisational culture on creativity and innovation in a university library.

[6] Kenny B, Reedy E, The Impact of Organizational Culture Factors on Innovation Levels in SMEs: An Empirical Investigation, The Irish Journal of Management, 2007, 5 (17): 119-142.

[7] Hofheinz P, policy brief "EU 2020: Why Skills are Key for Europe's Future”, 2009, p. 13.

[8] Tushman ML, O'Reilly, CA, Winning Through Innovation: A Practical Guide to Leading Organisational Change and Renewal, Harvard University Press, Boston, 1997.

[9] Martins EC, Terblanche F, Building Organisational Culture that stimulates Creativity and Innovation, European $\mathrm{J}$ of Innovation Management, 2003, 6 (1): 64-74.

[10] Zairi, M, Al-Mashari M, Developing a Sustainable Culture of Innovation Management: A Prescriptive Approach, Knowledge and Process Management, 2005, 12 (3): 190-200 